\title{
Briefing: Design for manufacture and off-site construction at Woolston Wastewater Treatment Works (UK)
}

\author{
Martin Tresidder BEng, CEng, MICE, MAPM, RPP \\ Chief Engineer, 4Delivery Site Office, Woolston WTW, Southampton, UK \\ (corresponding author: martin.tresidder@costain.com)
}

Paul White BSC, MSC, CEng, MICE

Senior Civil/Structural Engineer, Stantec UK, Buckingham Court, High Wycombe, UK

Due to numerous site physical constraints and a tight construction programme at Woolston Wastewater Treatment Works, UK, conventional design and construction practices are being challenged to deliver the project using off-site manufacturing wherever possible. Through early supplier engagement and collaboration, the team has developed design solutions to suit off-site fabrication: most of the permanent civil elements are to be supplied in precast concrete; larger mechanical elements are being designed in a modular arrangement; and mechanical and platform suppliers are developing these elements in factory conditions and delivering to the site with pipework and electrical elements pre-installed. By working within a building information modelling environment, the team manages supplier three-dimensional model sharing within a common data area, ensuring governance and version control. This enhances integration between suppliers, enabling early clash detection and providing confidence in the production of off-site elements. The adoption of an off-site manufacturing strategy has accelerated construction delivery, providing programme and cost savings, and improved the level of safety on-site through reduced working at height, temporary works requirements, lifting operations and plant and vehicle movements.

\section{Background}

The Woolston Wastewater Treatment Works (WwTW) was constructed in 1966 and treats flows from part of the Southampton conurbation, UK, for a population of 62000 . The existing site is based on a carbonaceous activated sludge plant (ASP) and suffers from a long-standing issue with odour that has affected the local population. In response to tighter environmental standards required by the Urban Wastewater Treatment Regulations 1994 and European Union's habitats directive (EC, 1992; HMG, 1994), Southern Water is undertaking a significant redevelopment of the site. As well as reducing the amount of total nitrogen that is discharged to the watercourse, this upgrade also seeks to address the odour problem.

The existing treatment works is located on a site of only 1.26 ha area. This physical constraint drove the need for a low-footprint process solution and has fully shaped the construction approach. The secondary treatment process involves use of a membrane bioreactor (MBR) in place of conventional final settlement tanks that would have required approximately four times the land area. The lack of available space for plant movement and storage of materials has required intricate planning to achieve the tight programme (Figure 1).

An additional challenge for the project was the need to maintain uninterrupted operation of the existing treatment process and achieve compliance against the existing treatment standards. With the lack of a nearby site with sufficient capacity, a pump-away solution was not feasible. Thanks to the availability of a small amount of land on an adjacent site, the project opted to construct a temporary treatment process to receive diverted flows and allow demolition of the existing works to proceed.
To tackle the physical and project schedule challenges, the Woolston team was required to develop a construction strategy that departed from conventional practice by applying factorythinking and delivering large elements of the scheme using offsite manufacturing techniques.

Work started on-site in late 2014 and is due for completion in 2019.

\section{Building information modelling}

The design team developed the project solution using a fully federated three-dimensional (3D) design model (Figure 2). This was critical for the team to address the site-specific constraints and develop a compact layout of plant and equipment while also maintaining safe access for operation and maintenance. The solution involved integration of over 60 supply chain designs, and the model enabled the team to manage the complex network of interfaces, avoid clashes and eliminate hazards. For example, welded stainless steel pipe sections were pre-assembled in large sections in a nearby factory and pump installations were mounted on skids to minimise site-based work in congested areas.

The level of detail captured in the model meant that it was a key tool in developing an efficient construction programme. This was particularly useful during collaborative planning workshops where site engineers and subcontractors could discuss the preferred installation sequences. In the early phases of the design, the model was presented to operational staff to ensure adequate provision of access for safe operation and maintenance.

Early supplier engagement was critical to the development of a design that was well-aligned with available process and 


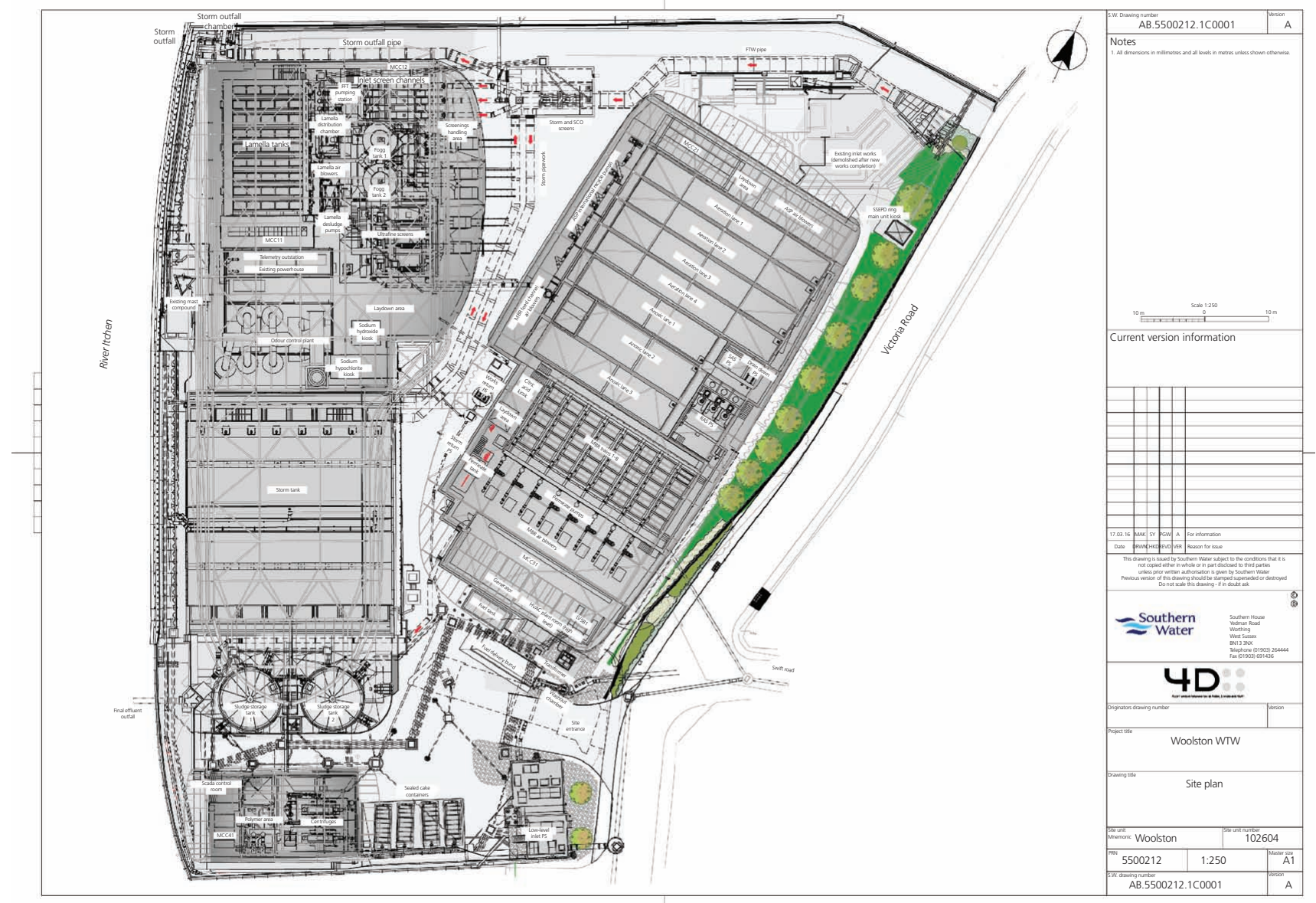

Figure 1. Woolston WTW site plan. (C Crown copyright 2018 Ordnance Survey. Media 053/18

mechanical plant. Key suppliers were invited to early design progress meetings to promote the use of standard equipment, define manufacturing constraints and simplify interfaces. This approach ensured that the scheme design that was developed with the supply chain in mind did not unnecessarily stress their capability and encouraged successful implementation on-site.

To facilitate the off-site approach, the design team shared models with the supply chain to enable them to design with consideration to interfacing plant and equipment. The data were managed with strict version control within a common data environment to ensure governance as the design developed. This also enhanced supplier awareness of hazards associated with installations outside of their own scope. By managing the model-sharing process, the team was well equipped to exercise its principal designer duties in accordance with the Construction (Design and Management) Regulations 2015 (HMG, 2015; HSE, 2015).

The design team used building information modelling (BIM) to develop an innovative checking and review tool. This allowed engineers to interrogate combined supplier designs within a $3 \mathrm{D}$ space and then select viewpoints to perform dimensional checks, annotation and capture comments. The tool was used as a means of communication between supply chain partners and enhanced design efficiency.

\section{Precast strategy}

Conventional in situ techniques were precluded as the space required for the site compound and material storage areas could not be accommodated within the small site footprint. With this as a driver, the design team sought to push precast techniques beyond anything it had attempted previously. To make this enterprise a success, the Woolston engineers were required to challenge and modify their standard approach to the design process.

A total of three significant structures were selected for this method, one of which was the large ASP and MBR structure. The nature of the site forced constrained working, and a programme schedule built around an in situ approach to this structure risked not meeting key client milestone dates. With the use of precast techniques, much of the physical effort required for construction can be relocated from the site and into a factory environment. 


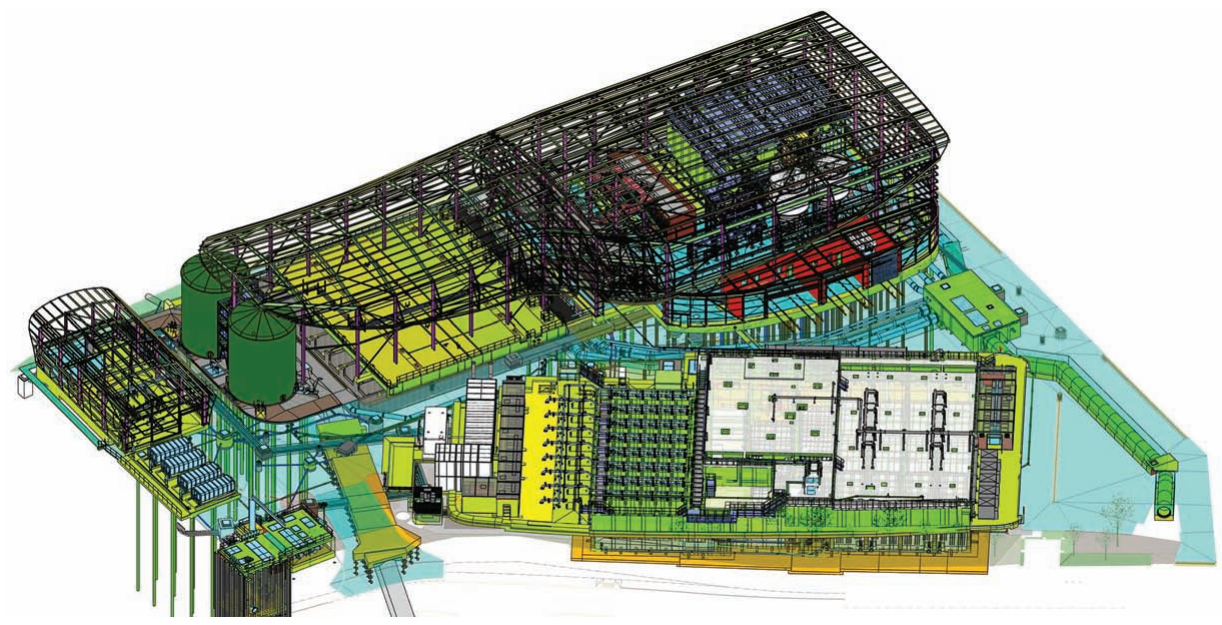

Figure 2. 3D model image of the new plant

\section{Precast concrete design}

The basic geometry of the ASP MBR structure was developed initially to suit a complex suite of process and hydraulic requirements, critical to successful performance and attainment of the required discharge standard. The designers developed a baseline 3D model that met these criteria and provided definition for the 'wet surfaces' of the structure.

To develop this design further, the Woolston design team then collaborated closely with the chosen precast concrete supplier early on to produce a structure suited to their preferred fabrication techniques. The first stage of this process was to split the structure into individual elements. The geometry of these units was based on existing wall unit moulds to maximise reuse and cost efficiency.

Critical hydraulic elements of the structure had undergone physical modelling and led to definition of irregularly shaped elements to create appropriate flow conditions and improve process performance. These items were communicated to the precast supplier through the $3 \mathrm{D}$ design model for creation of bespoke moulds. This brought great advantage over in situ techniques as the units were cast horizontally in flat beds and multiple pours could be executed safely and with greater accuracy.

Development of suitable precast element sizes occurred through close engagement between the supplier and site-based supervising staff to define acceptable lift limits. Close scrutiny was paid to the precast supplier's standard temporary works approaches to ensure that they met the standards of the principal contractor. For example, integral stabilising 'feet' were provided on the wall units to avoid the need for temporary props wherever possible. Coordination between temporary works design teams ensured that these were suited to local site conditions.

For odour containment, the 4Delivery design team decided to adopt a precast concrete cover system with a structural connection at the walls to create a propped cantilever. This was agreed early on with the precast supplier and reduced flexural reinforcement requirements. The supplier brought substantial expertise and experience in the use of admixtures for self-levelling and was able to produce very high-quality surfaces without the need for subsequent 'working' of the concrete.

\section{Precast installation}

The selected system is a modular method in which standard and bespoke precast wall elements are 'stitched' together with short sections of in situ concrete at site to create a monolithic structure.

The precast wall units were delivered and lifted directly into their permanent position by using a series of mobile cranes. This avoided the need for storage and double handling. Once the units were placed, an in situ base was constructed to fix them in place and form the wall moment connection. The stitch pours were formed with a shutter system using anchors precast into the wall units, giving a reliable and quick connection. As the structure was water retaining, the precast unit joint faces were delivered with aggregate exposed and a detail incorporating swelling water stops.

Utilisation of the precast method enabled execution of a large concrete structure with factory-standard finishes while avoiding some of the challenges of in situ construction. Numbers of operatives are typically reduced by two-thirds when compared with traditional in situ concrete construction techniques, which helps to minimise health and safety risks associated with on-site construction. The system helped mitigate specific hazards associated with working at height, temporary works, complex concrete pours, adverse weather conditions and movements of plant and vehicles.

Over $5500 \mathrm{t}$ of precast concrete elements were manufactured off-site, representing $65 \%$ of the walls to the main structure, saving over 350 concrete truck movements alone. Compared with 


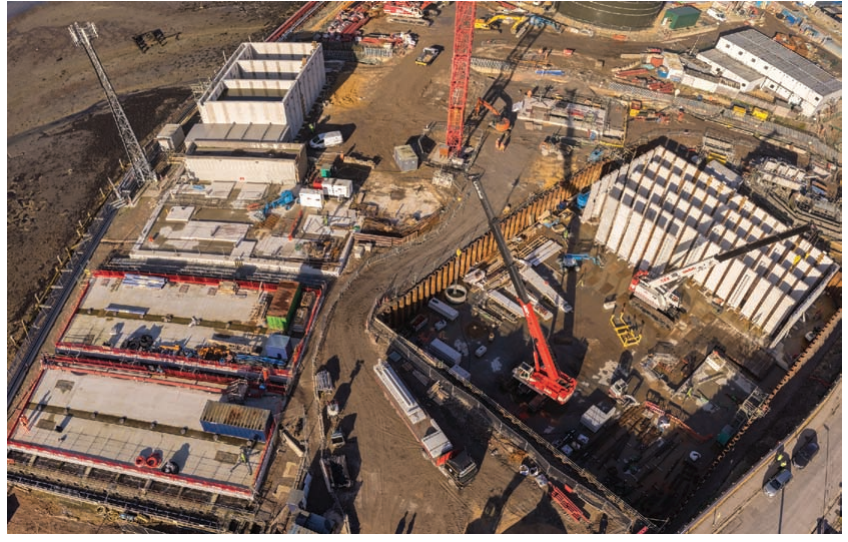

Figure 3. Photograph of precast structures during construction

in situ concrete construction, the project team estimates that overall there has been a minimum $30 \%$ reduction in vehicle and plant movements as a result of adopting this approach (Figure 3 ).

\section{Mechanical fabrication design}

Due to the works hydraulic profile, much of the mechanical equipment at Woolston is above building ground-floor levels. To meet maintenance requirements and to ensure safe access and egress, a complex arrangement of structural steelwork, access platforms, staircases, pipework and cable routing was required.

A detailed and considered approach was required to facilitate the design, incorporating more than 30 independent 3D mechanical models within a heavily congested floor-level plant layout. Management of the interfaces was critical to integrate the mechanical, electrical and civil designs and achieve a harmonised and cost-effective solution.

The application of off-site fabrication meant reduced numbers of onsite personnel, total man-hours and high-risk construction activities such as welding. This approach took a number of forms, including skid-based designs for transportation by lorry, steel process tanks in both single-unit and bolted construction formats, pre-assembled flooring assemblies and welded pipework to flanged termination points. Design of modular parts considered interface terminations, installation sequence, size, weight/lifting and component repetition to facilitate the off-site approach. Factory-based inspection and integrity testing was adopted wherever possible.

With the project now entering the mechanical installation phase, it is expected that the combination of these methods will allow for safer working conditions and achievement of more efficient on-site delivery.

\section{Conclusion}

The WwTW project is one of Southern Water's largest investment projects currently underway. The project team has adopted an offsite strategy to address the numerous site constraints.

Use of this approach has allowed works to be undertaken in controlled factory settings, increasing the quality of the civil and mechanical installation. Based on experience from recent projects of a similar scale, the site team has reported a reduced number of construction issues and lost time compared with conventional on-site techniques.

The design was developed specifically with this method in mind and pushed usage of BIM techniques to make this happen efficiently. The high level of planning and coordination with the supply chain has been critical to the process, thus helping ensure that the scheme can be delivered quickly and, above all, safely.

\section{REFERENCES}

EC (European Community) (1992) Council Directive 92/43/EEC on the conservation of natural habitats and of wild fauna and flora. Official Journal of the European Union L206.

HMG (Her Majesty's Government) (1994) The Urban Waste Water Treatment (England and Wales) Regulations 1994. The Stationery Office, London, UK, Statutory Instrument 1994 No. 2841.

HMG (2015) Construction (Design and Management) Regulations 2015. The Stationery Office, London, UK, Statutory Instrument 2015 No. 51. HSE (Health Safety Executive) (2015) Construction (Design and Management) Regulations 2015. HSE, Bootle, UK.

\section{How can you contribute?}

To discuss this paper, please email up to 500 words to the editor at journals@ice.org.uk. Your contribution will be forwarded to the author(s) for a reply and, if considered appropriate by the editorial board, it will be published as discussion in a future issue of the journal.

Proceedings journals rely entirely on contributions from the civil engineering profession (and allied disciplines). Information about how to submit your paper online is available at www.icevirtuallibrary.com/page/authors, where you will also find detailed author guidelines. 